\title{
Paediatric ovarian torsion: a case report and review of literature
}

\author{
Umang $^{1 *}$, Harleen Kaur Cheema ${ }^{1}$, Sidharth Khullar ${ }^{2}$, Madhu Nagpal ${ }^{1}$
}

\begin{abstract}
${ }^{1}$ Department of Obstetrics and Gynecology, Sri Guru Ramdas Institute of Medical Sciences and Research, Amritsar, Punjab, India

${ }^{2}$ Department of Surgery, Sri Guru Ramdas Institute of Medical Sciences and Research, Amritsar, Punjab, India
\end{abstract}

Received: 29 March 2020

Accepted: 29 April 2020

\author{
*Correspondence: \\ Dr. Umang, \\ E-mail: drumangkhullar@gmail.com
}

Copyright: $\odot$ the author(s), publisher and licensee Medip Academy. This is an open-access article distributed under the terms of the Creative Commons Attribution Non-Commercial License, which permits unrestricted non-commercial use, distribution, and reproduction in any medium, provided the original work is properly cited.

\begin{abstract}
Ovarian torsion is a surgical emergency, can result in ovarian loss, intra-abdominal infection and even death. Paediatric ovarian torsion is a rare condition, requires high clinical suspicion and prompt diagnosis. Diagnosis is a challenge since signs and symptoms are similar to those of other causes of acute abdominal pain such as appendicitis, gastroenteritis, urinary tract infection, renal colic or other conditions of acute abdominal and pelvic pain. Here, authors describe a case of a 4-year-old girl with a presentation of acute abdominal pain, treated empirically elsewhere. After investigations, a provisional diagnosis of ovarian torsion was made and patient was taken up for surgery. Intraoperatively, ovary was found to be necrosed. Detorsion was tried but ovary was unsalvageable. Right sided salpingectomy with oophorectomy was performed. Conservative surgery by laparoscopic detorsion can be tried in cases of ischemia but if necrosis has already set in, then salpingo-oophorectomy has to be performed.
\end{abstract}

Keywords: Acute abdominal pain, Paediatric ovarian torsion, Salpingo-oophorectomy

\section{INTRODUCTION}

Acute pain localized in right iliac fossa is an emergency situation requiring urgent response in female child. Typically, one tries symptomatology fitting into appendicitis or urinary tract infection but if there is no fever or localisation of pain - other causes should be ruled out. Paediatric ovarian torsion represents a rarest true unthinkable surgical emergency.

Ovarian torsion can be a catastrophic emergency, especially if ovarian salvage is not possible. Pathological complications of ovarian torsion are ovarian loss, intraabdominal infection, sepsis and even death.

It can have great psychological impact. ${ }^{1,2}$ Ovarian torsion accounts for $2.7 \%$ of all cases of acute abdominal pain in children. The incidence in women less than 20 years of age is 4.9 per 1 lac. $^{3}$ Ovarian salvage requires high clinical suspicion. Reason for delay is "not suspecting" it in children. Ovarian torsion is the twisting of an ovary on its ligamentous supports and results in a compromised blood supply. Adnexal torsion includes either twisting of the ovary, fallopian tube or both. ${ }^{4}$ Torsion is more common on right side, possibly either because of the sigmoid colon limiting the movement on left side or a hypermobile caecum on the right side and could also be due to longer ovarian ligament. ${ }^{5}$

Diagnosis is revealed by ultrasonography only. The features of ovarian torsion include a unilateral enlarged ovary, uniform peripheral cystic structures, a coexistent mass within the affected ovary, free pelvic fluid, lack of arterial or venous flow and a twisted vascular pedicle.

The presence of flow at colour doppler imaging does not reliably exclude torsion but instead suggest that the ovary may be viable. ${ }^{4}$ 


\section{CASE REPORT}

\section{History}

Authors received a patient in emergency, 4 years female (MRD number-423251), with chief complaint of acute pain right iliac fossa since 2 days. The pain was constant, non-radiating, not relieved with analgesics. Patient also had complaint of fever $100.8 \mathrm{~F}$, non- spiky with no rigors and chills. There was also associated vomiting, three episodes in 2 days, non-bilious, non-projectile. There was no history of urinary retention, frequency, urgency, diarrhea or constipation. There was no history of sore throat, skin rash, abnormal body movements. There was history of admission in private hospital one day back where she was given intravenous antibiotics with no relief of pain or fever. There was no significant past history. There was no similar family history. On general physical examination, patient was anxious, noncooperative, oriented to time, place and person, thin built, looked in agony with pulse- $110 / \mathrm{min}, \mathrm{BP}-110 / 70 \mathrm{mmHg}$, Temp- $100{ }^{\circ} \mathrm{F}$, RR- $28 / \mathrm{min}$, respiratory rate $18 / \mathrm{min}$, regular. On per abdomen examination, -inspectionnormal shape, no dilated veins, umbilicus inverted, no scar mark, on palpation -abdomen was guarded, tenderness present over right iliac region, no organomegaly, On percussion- Tympanic note present, no shifting dullness.

On auscultation- bowel sounds present.

On Investigations, Hb-10.4 gm\%, TLC- 8600/cumm, DLC- $75 / 22 / 01 / 02$,

Urine routine examination - 1-2 pus cells.

Liver function tests- within normal limits, renal function tests- within normal limits, CA-125 - $1.2 \mathrm{U} / \mathrm{ml}$, AFP- 6 $\mathrm{ng} / \mathrm{ml}$. On ultrasonography - upper abdomen normal, uterus size, $2.2 \times 1.3 \times 0.7 \mathrm{~cm}$ (pre-pubertal size), enlarged right ovary, $3.7 \times 2.4 \times 1.9 \mathrm{~cm}, 9 \mathrm{ml}$ volume, adnexae thickened. On colour Doppler, low vascularity seen in the ovary. Left ovary could not be visualized.

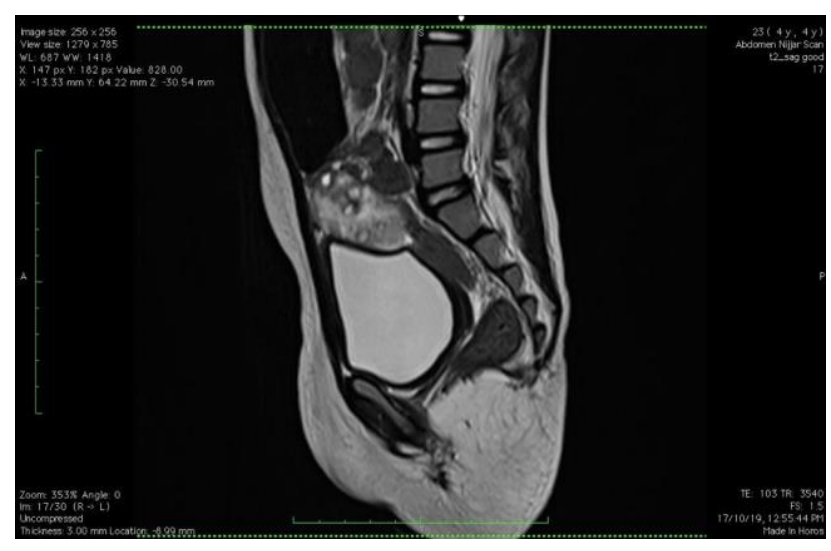

Figure 1: MRI appearance of torsion ovary.
On MRI- uterus a/v, normal for age, enlarged swollen right ovary, measuring $4.3 \times 2.7 \times 2.35 \mathrm{~cm}$, stroma hyperintense on T2W suggestive of oedema. Few T2 hypointensities also noted suggestive of hemorrhages. Adjacent fallopian tube thickened, oedematous and twisted over ovary.

Another ovary not clearly identified. Mild free fluid seen in the pelvis (Figure 1, Figure 2).

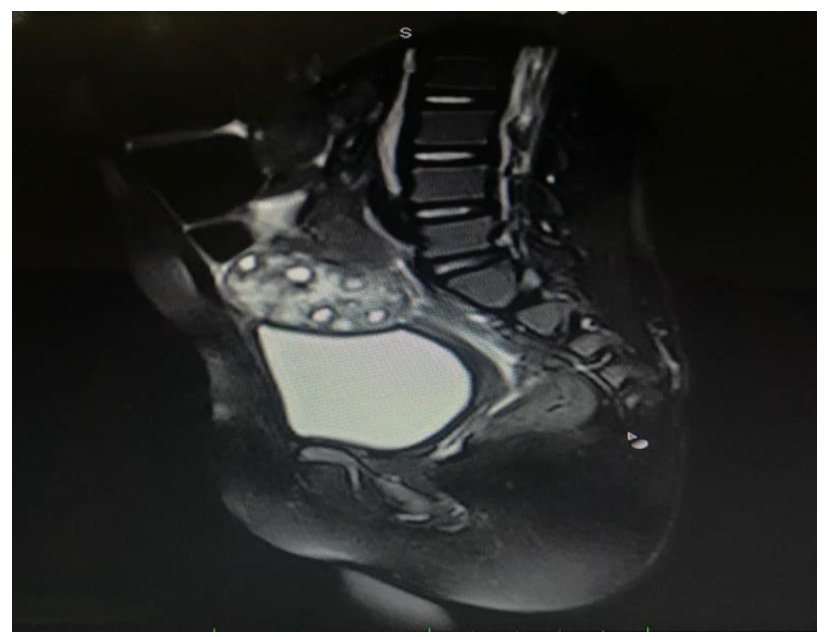

Figure 2: MRI appearance of torsion ovary.

Patient was counselled for risk and consequences related to ovarian torsion, delayed diagnosis and delayed management. Informed consent of ovarian salvage or sacrifice was taken. Exploratory laparotomy was done. Intra operatively, necrosed right ovary was identified (Figure 3).

Detorsion was tried, warm saline mopping was done for 15 minutes but no change of colour was noted. Right sided salpingectomy with oophorectomy was performed. On histopathology, twisted, necrosed ovarian cyst and twisted fallopian tube seen. Postoperative recovery was uneventful.

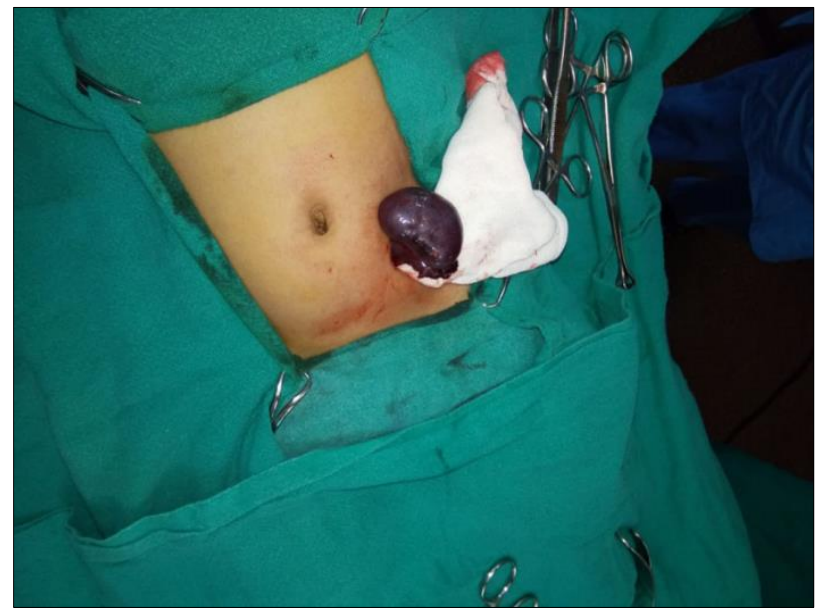

Figure 3: Intraoperative of discoloured adnexa. 


\section{DISCUSSION}

Pediatric ovarian torsion is an uncommon cause of acute abdominal pain in children. Ovarian torsion is a rare problem within the paediatric population, but is a true gynecological and surgical emergency. ${ }^{1,2}$ Ovarian torsion accounts for approximately $2.7 \%$ of all cases of acute abdominal pain in children. ${ }^{6,7}$ Preoperative diagnosis is a challenge since signs and symptoms are similar to those of other causes of acute abdominal pain such as appendicitis, gastroenteritis, urinary tract infection, renal colic or other conditions of acute abdominal and pelvic pain. ${ }^{8}$

The normal mobility of the fallopian tube can lead to rotation of ovary along with its vasculature. This leads to obstruction of venous outflow, infarction and eventual necrosis, infection, peritonitis or loss of adnexa.

Torsion is more common on right side. Torsion occurs frequently on the right side presumably because the sigmoid colon leaves limited space for adnexal movement on left side or a longer ovarian ligament on right side..$^{5,6,9}$

Ultrasound is the most useful initial diagnostic modality, but the absence of flow on colour doppler is not always present. Ultrasound is the best initial investigation as it is readily available, no radiation exposure and can differentiate from other common causes of acute abdominal pain. ${ }^{10}$

CT scan and MRI imaging can be used to diagnose ovarian torsion if not confirmed on ultrasonography. Subacute ovarian haemorrhage and abnormal enhancement is usually seen as their characteristic patterns on CT scan and MRI. ${ }^{10}$

Management can be conservative, which preserves the ovary. Conservative surgical options include detorsion and oophoropexy, which are favored presently in $28 \%$ to $45 \%$ cases. $^{11}$ Normal ovarian volume till puberty is $1 \mathrm{cc}$ each. Tubes are thin slender, not visualized on routine USG however normal tubo-ovarian relationship to uterus can be commented.

Pain lasting for more than 10 hours is associated with increased risk of tissue necrosis. Detorsion performed within 72 hours of torsion usually preserves normal ovarian function. ${ }^{12}$ Tubal salvage rates in literature are variable. Functional performance of ovaries in postmenarche period is important.

\section{Surgical options}

Resection of ovary without detorsion was done in the past due to fear of thromboembolism, adhesions due to inflammatory effect of necrosed ovary, bowel obstruction or leaving malignancy in situ. Ovarian torsion, previously treated by laparotomy and oophorectomy, often can be managed conservatively by laparoscopic approach. ${ }^{13,14}$ The adnexa can be untwisted, even in the presence of visible necrosis, resulting in preservation of ovarian function. ${ }^{15,16}$ Detorsion alone can be considered despite the macroscopic appearance of ovary and follow-up with ultrasonography.

Typical ultrasound findings include an enlarged ovary or mass, free fluid, thickening of cyst wall, twisted pedicle; although up to $5 \%$ of torsioned ovaries have been reported to be of normal size.$^{17}$ On doppler sonography, if arterial or venous blood flow is present, ovarian torsion cannot be excluded, as there is dual blood supply of ovary from ovarian and uterine arteries which provide persistent arterial blood flow and clinical features may result from venous engorgement before arterial blood supply is interrupted. ${ }^{12,17}$

Laparoscopic surgery is considered the best diagnostic and therapeutic approach. Use of laparoscopy as a diagnostic modality should be preferred particularly in paediatric patients with pelvic pain and a pelvic mass of more than $5 \mathrm{~cm}$, as it increases the chances of ovarian salvage. ${ }^{18}$

\section{CONCLUSION}

Ovarian torsion can occur at any age. Therefore, a high index of suspicion along with clinical features and radiological evidence will facilitate prompt diagnosis and ovarian salvage with significantly reduced patient comorbidity.

Conservative management of torsion via laparoscopy is the preferred management and will preserve ovarian function, allowing the subsequent normal progression through puberty and future fertility. Follow-up after 6 weeks is done with sonography, showing normal vascularity and follicular development in salvaged ovary.

Clinical outcome, long term follow-up of patients managed conservatively showed rates of normal sized ovaries and follicular function as high as $91-98 \%$.

In the present case, since the patient reported late, precious time was lost till final diagnosis was made and as such, the ovary could not be salvaged. Counselling and informed consent are important components of management. Future note of single ovary in reproductive age is necessarily emphasised.

Funding: No funding sources

Conflict of interest: None declared

Ethical approval: Not required

\section{REFERENCES}

1. Breech LL, Hillard PJA. Adnexal torsion in pediatric and adolescent girls. Current Opin Obstet Gynecol. 2005; 17:483-9. 
2. Aziz D, Davis V, Allen L, Langer JC. Ovarian torsion in children: is oophorectomy necessary? J Pediatr Surg. 2004;39:750-3.

3. Bridgette DG, Mark DA, Elizabeth CP. Incidence and trends of paediatric ovarian torsion hospitalisations in the United States, 2000-2006. Paediatr. 2010;125:532.

4. Hannah CC, Shweta B, Vikram SD. Pearls and pitfalls in diagnosis of ovarian Torsion. Radio Graph. 2008;28:1355-68.

5. Nicolas DH, Julina DJ. Torsion of the adnexa. Clin Obstet Gynecol. 1985;28:375-80.

6. Hibbard LT. Adnexal torsion. Am J Obstet Gynecol. 1985;152:456-61.

7. Hoey BA, Stawicki SP, Hoff WS, Veeramasuneni RK, Kovich H, Grossman MD. Ovarian torsion associated with appendicitis in a 5-year-old girl: a case report and review of the literature. J Pediatr Surg. 2005;40(9):e17-20.

8. Pomeranz AJ, Sabnis S. Misdiagnoses of ovarian masses in children and adolescents. Paediatr Emerg Care. 2004;20:172-4.

9. Albayram F, Hamper UM. Ovarian and adnexal torsion: spectrum of sonographic findings with pathologic correlation. J Ultrasound Med. 2001;20:1083-9.

10. Mishra V, Hokabaj S, Roy P, Aggarwal R, Vyas B, Mehta N. Case series of paediatric adnexal torsion: rare yet urgent entity. Int J Reprod Contracept Obstet Gynecol. 2017;6:315-9.

11. Claudio $S$, Irene $B$, Valentina $P$, Josephine $L$, Elisabetta A, Luca N. Adnexal torsion in children and adolescents: new trends to conservative surgical approach: our experience and review of literature. Gynecol Endocrinol. 2013;29:1.

12. Poonai N, Poonai C, Lim R, Lynch T. Paediatric ovarian torsion: case series and review of literature. Canadian J Surg. 2013;56(2):103-8.

13. Mage G, Canis M, Manhes H, Pouly JL, Bruhat MA. Laparoscopic management of adnexal torsion. A review of 35 cases. J Reprod Med. 1989;34(8):520-4.

14. Vancaillie T, Schmidt EH. Recovery of ovarian function after laparoscopic treatment of acute adnexal torsion. A case report. J Reprod Med. 1987;32(7):561-2.

15. Galinier P, Carfagna L, Delsol M, Ballouhey Q, Lemasson F, LeMandat A, et al. Ovarian torsion Management. Paediatr Surg. 2009;44(9):1759-65.

16. Cohen SB, Oelsner G, Seidman DS, Admon D, Mashiach S, Goldenberg M. Laparoscopic detorsion allows sparing of the twisted ischaemic adnexa. J Am Assoc Gynecol Laparosc. 1999;6(2):139-43.

17. Shauna D, Esther O, Sussana IL. Ovarian torsion: diagnostic features on $\mathrm{CT}$ and MRI with pathologic correlation. Am J Roentgenol. 2012;198(2):122-31.

18. Oltmann SC, Fischer A, Barber R, Huang R, Hicks B, Garcia N. Cannot exclude torsion- a 15-year review. J Pediatr Surg. 2009;44(6):1212-6.

Cite this article as: Umang, Cheema HK, Khullar S, Nagpal M. Paediatric ovarian torsion: a case report and review of literature. Int J Reprod Contracept Obstet Gynecol 2020;9:2638-41. 